\title{
LIQUID LIMIT VALUES OBTAINED BY DIFFERENT TESTING METHODS
}

\author{
Kollaros G. ${ }^{1}$ \\ ${ }^{1}$ Democritus University of Thrace, Department of Civil Engineers, 67130, Xanthi, Greece, \\ gkoll@civil.duth.gr
}

\begin{abstract}
Specifications in European countries include a variety of methods for determining the liquid limit based on Casagrande type devices and on the fall cone penetrometer. The results of a comparative study of the liquid limits determined using these two fall-cone methods are presented for lime stabilized soil. Soil material sampled in the area of Evros Regional Unit has been stabilized with lime in order to enhance its engineering characteristics. The soil and the soil-lime mixtures subjected in Atterberg limit testing. The liquid limit values were correlated through a linear regression analysis with the rest of the consistency limits of both the natural soil and its mixtures with various lime contents. The correlation coefficients in all cases were high, with those referring to results obtained by the Casagrande method to be dominant. The comparison of liquid limit values determined by either method showed that there is a systematically good correlation between them, with the decrease rate in function of the lime content in the mixture to be more intense in the case of the drop-cone procedure. There is a need for a universal specification for the determination of the consistency limits.
\end{abstract}

Keywords: Atterberg limits, fall cone penetrometer, regression analysis, soil stabilization, additive material.

\section{Пєрí $\eta \psi \eta$}

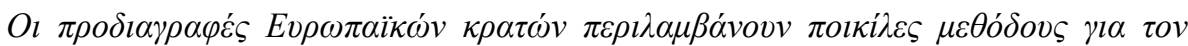

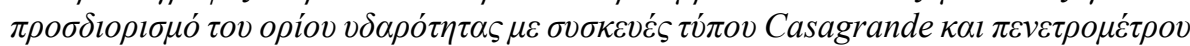

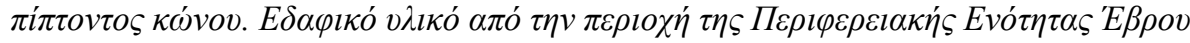

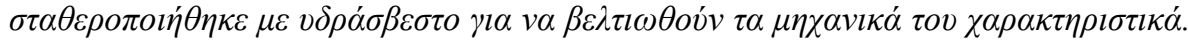

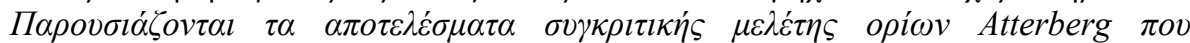

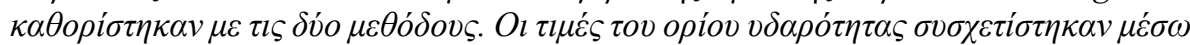

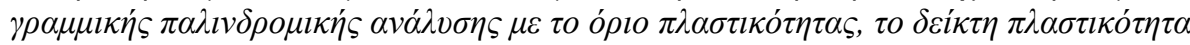

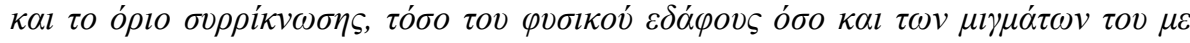

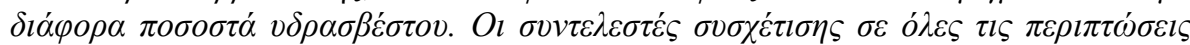

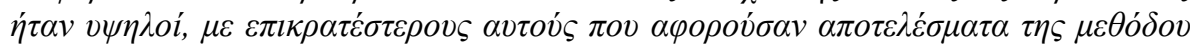

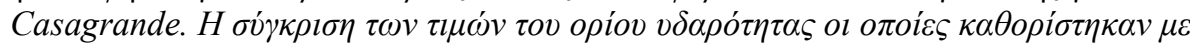

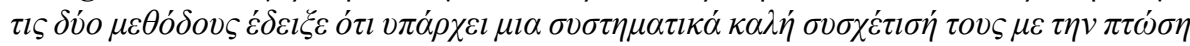

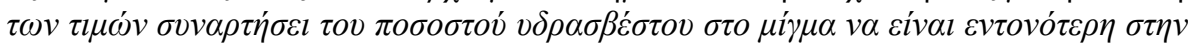

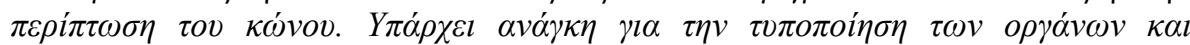

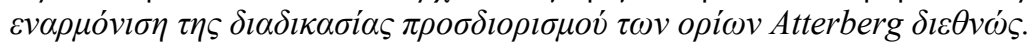

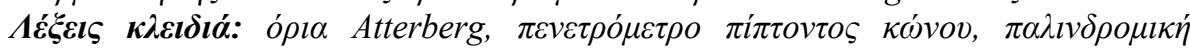

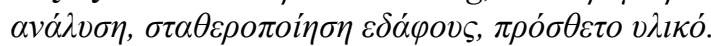




\section{Introduction}

The consistency limits (liquid limit, LL, plastic limit, PL and shrinkage limit, SL) are related to the amount of water attracted to the surface of the soil particles and are predominant factors for identifying and classifying a soil. Relatively simple methods have been proposed to determine the liquid limit; the most important are the Atterberg percussion or Casagrande (1932) method and the fall cone penetrometer method. The classical method is described by ASTM D-4318 and the fall cone method by BS 1337:2. This last method is becoming more popular due to different inherent weaknesses of the Atterberg method as many researchers -and Casagrande himself- (Casagrande 1958) have discussed.

In the fall cone method, liquid limit is the moisture content corresponding to a specified depth of penetration for a cone of known geometry and weight. Detailed examination of the potential of the fall cone method (Karlsson, 1961; Sherwood and Ryley, 1970; Campbell, 1975; Leroueil and Le Bihan; 1996; Farrell et al., 1997; Quintela et al., 2014) has lead to the suggestion that the cone method presents a more reliable and reproducible indirect measure of soil strength at liquid limit.

A theoretical study of the fall cone test (Houlsby, 1982) considered various factors such as cone bluntness, cone roughness and deviations in the apex angle, and the basic conclusions drawn refer to (a) the significant effect the roughness of the cone has on the measured shear strength and (b) to an optimum angle of 52.6' for a smooth cone of fixed cross-sectional area to penetrate the surface of a cohesive soil.

In an experimental work (Emami and Monfared, 2012) the effect of various fall cone parameters (ex. cone apex angle, diameter, overload, cone surface roughness) on Atterberg limits of both homogeneous and non-homogenous (layered) type soil samples has been investigated. The liquid limit of cohesive clayey silt as well as silty-clay soil samples were determined based on fall cone tests with four different cones with $30^{\circ}$ and $60^{\circ}$ apex angles, two different diameters and also different surface roughness. The results showed that the apex angle of cone may play a more important role in determining the LL of soil.

The effect of clay content on the liquid limit has been studied by numerous researchers through the use of the fall cone and the Atterberg device (Nini, 2014). The use of a British cup had lead to the notice that soil samples with clay content lower than $50 \%$ exhibit fall-cone liquid limit values higher than those of the Atterberg cup (Budhu, 1985). The same tendency to the laboratory results is found in other researches as well (Sherwood and Ryley, 1970).

Liquid and plastic limit are suggested as moisture contents determined at penetration depths of 20 $\mathrm{mm}$ and $2.8 \mathrm{~mm}$, respectively. When the fall cone penetrometer readings are used, then liquid and plastic limits, as well as plasticity index, are found leading to a considerable saving in testing time. This makes the method more precise than the standard one. The use of a cone penetrometer to determine not only the liquid limit, but also the plasticity index has been proposed (Belviso et al., 1985). The plastic limit can then be obtained as the numerical difference between liquid limit and plasticity index.

A wide range of soils in New Zealand were subjected to Atterberg limits tests and had shown a close correlation between the fall cone penetrometer method and standard methods (Allbrook, 1980).

Investigators have shown that -at least with two types of fall cones- the differences between fall cone liquid limit values and cup liquid limit values were not large. Many countries have adopted the fall cone as a standard device. Therefore, it is very important to make a comparison between the values of both methods for geotechnical works.

Aiming to contribute to the discussion about the differences and the relationships between the two conventional methods used to determine LL, a comparison and assessment of the liquid limit of a swelling soil from Thrace region, N. Greece, has been determined by Casagrande percussion cup and fall cone method. The procedure has been conducted by the same operator and the same 
instruments in order to avoid possible discrepancies due to experience, manual skills, and practice of the operator or the sensitivity of the equipment. In order to minimize the factors involved in the testing, a single soil has been chosen.

A suitable for road construction soil is required to exhibit reduced volume changes due to moisture variation. The plasticity index plays a basic role in that condition. Hence, every process reducing PI is beneficial. The stabilization of soils with the addition of substances such as lime contributes to this goal through the grain agglomeration and the formation of new crystalline compounds. The liquid limit values were also determined for soil-lime mixtures with various additive contents.

\section{Materials and Methods}

Dark grayish soil samples were collected for the laboratory investigation. The sampling area is located in a plain region of Northern Evros Regional Unit, near Orestiada. The local name of the site, where -after the removal of surface grass and lose soil- an excavation about $1 \mathrm{~m}$ deep has been made, is "Stachtes". The grain size distribution of the selected clayey soil has been determined employing both the dry method (ASTM D-6913) and hydrometer analysis. The sieve analysis was performed in order to find the sandy and gravelly fractions. The hydrometer was used according to ASTM D-422 in order to determine the silt and clay fractions. By applying Stokes' law, the silt and clay fractions were obtained. The grain size distribution of the soil is shown in Figure 1.

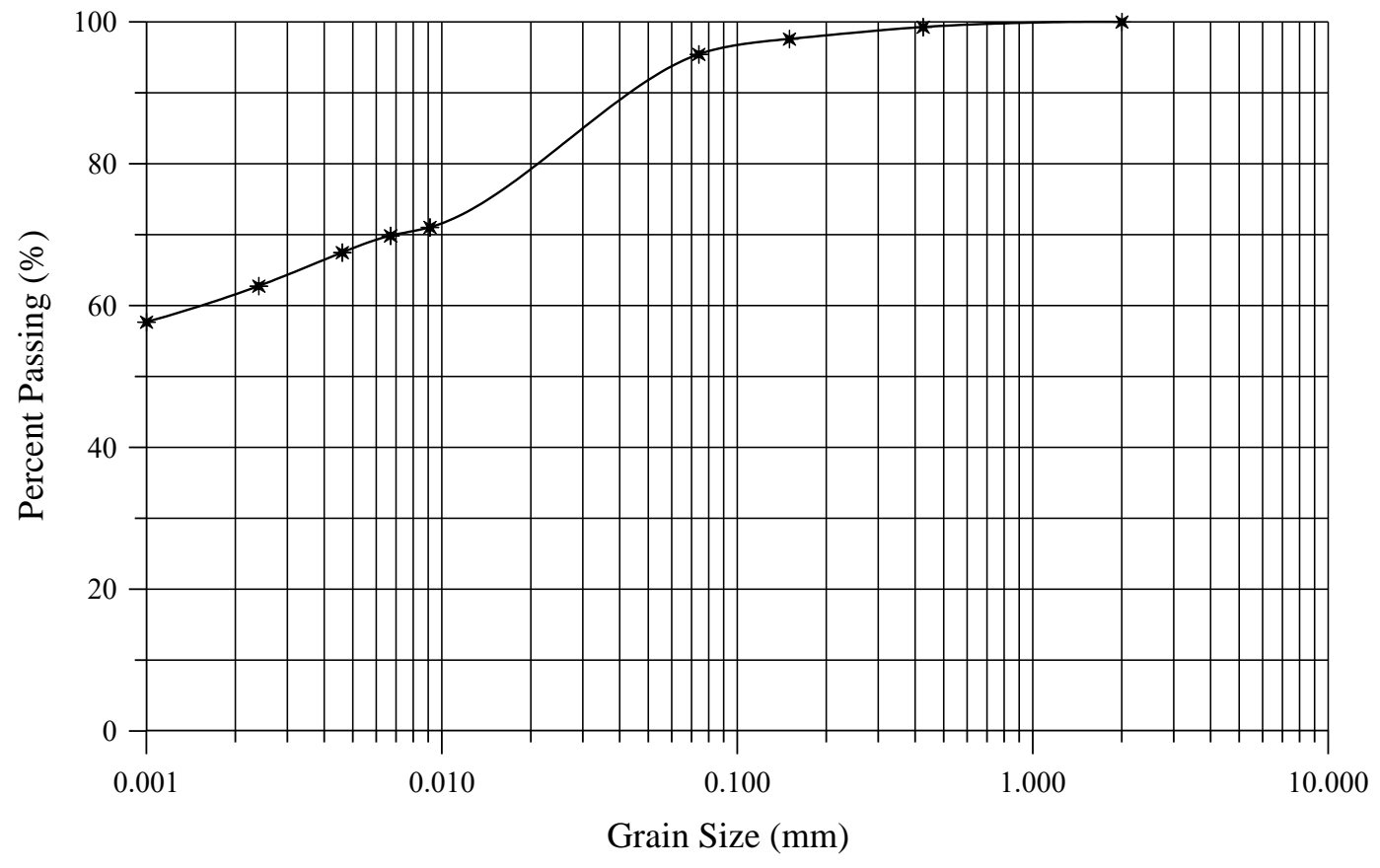

Figure 1 - Grain size distribution of the soil tested.

The soil tested is classified as Group A-7-6 according to the AASHTO classification system, while, according to the Unified Classification System, is classified as $\mathrm{CH}$. The suitability of such soils as subgrades in pavement construction is judged as fair to poor. The chemical properties of the soil tested are shown in Table 1. The silica oxide was the prevalent compound with a percentage $64.18 \%$, while the aluminum oxide was also present in a high percentage.

Lime used for the stabilization process was a common commercial lime supplied in bag-packing by a company located in Drama prefecture, Northern Greece. The chemical properties of the lime used are also shown in Table 1 . The content of calcium oxide in lime was found to be $65.25 \%$ and the loss on ignition reached a value of $33.25 \%$. 
Table 1 - Chemical properties of soil and lime.

\begin{tabular}{|l|l|l|}
\hline & Soil & Lime \\
\hline Loss on Ignition (\%) & 11.12 & 33.25 \\
\hline $\mathrm{SiO}_{2}$ & 64.18 & 0.01 \\
\hline $\mathrm{Al}_{2} \mathrm{O}_{3}$ & 13.50 & 0.01 \\
\hline $\mathrm{Fe}_{2} \mathrm{O}_{3}$ & 4.57 & 0.11 \\
\hline $\mathrm{CaO}$ & 1.40 & 65.25 \\
\hline $\mathrm{MgO}$ & 1.16 & 0.50 \\
\hline $\mathrm{K}_{2} \mathrm{O}$ & 2.30 & 0.01 \\
\hline $\mathrm{Na}_{2} \mathrm{O}$ & 1.35 & 0.01 \\
\hline
\end{tabular}

The clay soil sampled in Evros Regional Unit had been air dried. Mixtures of the soil fraction passing the No. 40 sieve with lime had been prepared on the basis of additive percentages differing by $2 \%$ by soil weight from each other, starting from $2 \%$ and ending up to $10 \%$. The mixtures were left to cure for about half an hour prior being tested.

For all soil-lime admixtures the Atterberg limits were determined along with the linear shrinkage. The linear shrinkage was calculated using semicircular specimens having a length of $140 \mathrm{~mm}$ and $12.5 \mathrm{~mm}$ radius in stainless steel moulds. Soil samples mixed with water up to the liquid limit value were placed in the moulds, according to BS 1377:Part 2:1990 specification. Their length was measured after 10 days in ambient air conditions. The ratio of the difference of the two measurements to the initial length yielded the value of linear shrinkage.

In order to establish the liquid limit values of the soil and the soil-lime mixtures, the standard procedures described for the Atterberg limits in ASTM D 4318-10e1 were followed. LL determined with the fall cone method (BS 1377: Part 2: 1990) is the quantity of moisture where a standard cone freely falling for $5 \mathrm{sec}$ after its release penetrates $20 \mathrm{~mm}$ in sample.

The plasticity index (PI) is defined as the difference between the liquid and plasticity limits and is a value used for the recognition of soil characteristics and the proper soil classification. PI determines the suitability of soils to be used as subgrades in roadway foundations.

\section{Results and Discussion}

The liquid limit of the soil and its mixtures with various lime contents was found using the Casagrande and fall cone methods. The liquid limit values decreased with the addition of lime. The rate of change was more intense in the case of the cone method than when the Casagrande tests were performed.

For the different additive contents, the LL values ranged in the intervals $77 \%$ to $56 \%$ and $75 \%$ to 53\% when the Casagrande and fall cone methods were used, respectively. The variation in Liquid Limit with the addition of lime in various proportions is shown in Figure 2. The rate of decrease was higher in the first step of lime admixture. After $2 \%$ lime added, the variation was milder in both cases.

The plastic limit gradually increased from $31 \%$ to $47 \%$ with the addition of lime in percentages from 2 to $10 \%$ per solid soil weight. The decrease in plasticity index values is mainly due to the decrease of LL values. 


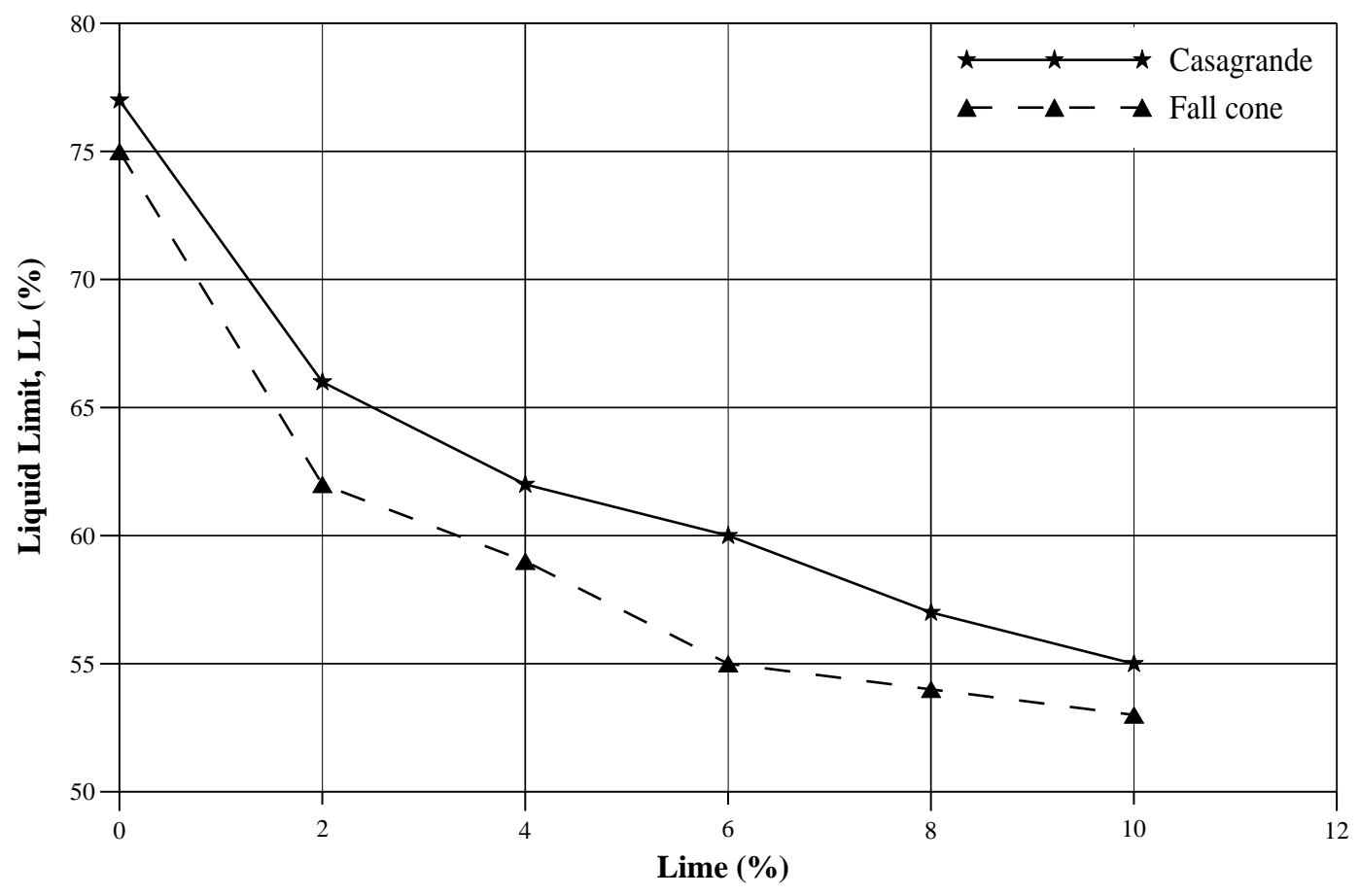

Figure 2 - Variation of Liquid Limit for different additive contents in soil-lime mixtures.

The admixture of lime caused an increase in the plastic limit, while both the liquid limit and the plasticity index of the soils have been reduced. The immediate effect of lime addition to the soil is to cause flocculation and agglomeration of the clay particles due to cation exchange at the surface of the soil particles (Athanasopoulou, 2014). The result of this short-term reaction is to enhance workability and plasticity.

The linear shrinkage values recorded showed a trend to be lower $(19.7 \%$, for the soil to $7.8 \%$ for $10 \%$ by weight lime added) with the admixture of higher lime contents, leading to enhanced swelling characteristics. Lime significantly reduces the response of clay minerals to water as a result of the formation of crystalline compounds on their surface, as well as of lime intrusion in the areas between the layers; in such a way the swelling properties of the material are inhibited (Athanasopoulou and Kollaros, 2011; Saeed et al., 2013).

The liquid limit values were correlated through a linear regression analysis with the rest of the consistency limits. The results shown in figures 3 to 5 present very good correlation coefficients, $r$, ranging from 0.92 to 0.99 . The correlation of LL and PL, PI, and LS values depicted in figures 3, 4 and 5 respectively could be expressed by the equations listed in Table 2.

Table 2 - Equations for PL, PI, and LS correlated to LL.

\begin{tabular}{|l|l|l|}
\hline Indices Correlated & \multicolumn{1}{|c|}{ Equation } & Correlation coefficient, $r$ \\
\hline Fall cone method & PL $=-0,72 \times$ LL +82.84 & 0.94 \\
\hline PL-LL & PI $=1.72 \times$ LL -82.84 & 0.99 \\
\hline PI-LL & LS $=0.56 \times$ LL -20.18 & 0.92 \\
\hline LS-LL & PL $=-0,76 \times$ LL +87.63 & 0.96 \\
\hline Casagrande & PI $=1.76 \times$ LL -87.63 & 0.99 \\
\hline PL-LL & LS $=0.60 \times$ LL -24.48 & 0.92 \\
\hline PI-LL & LS-LL
\end{tabular}




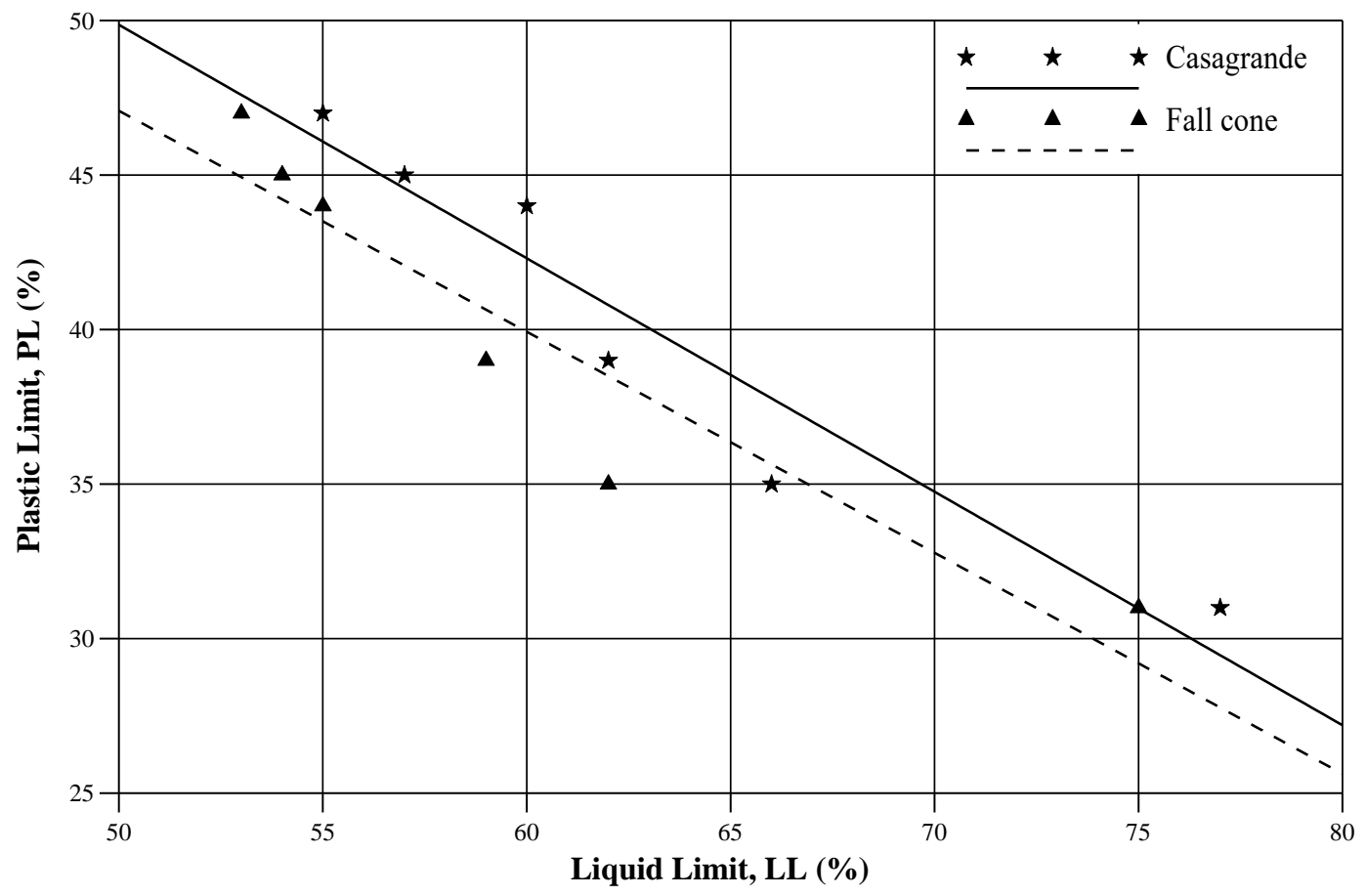

Figure 3 - Correlation of Liquid Limit and Plasticity Limit values.

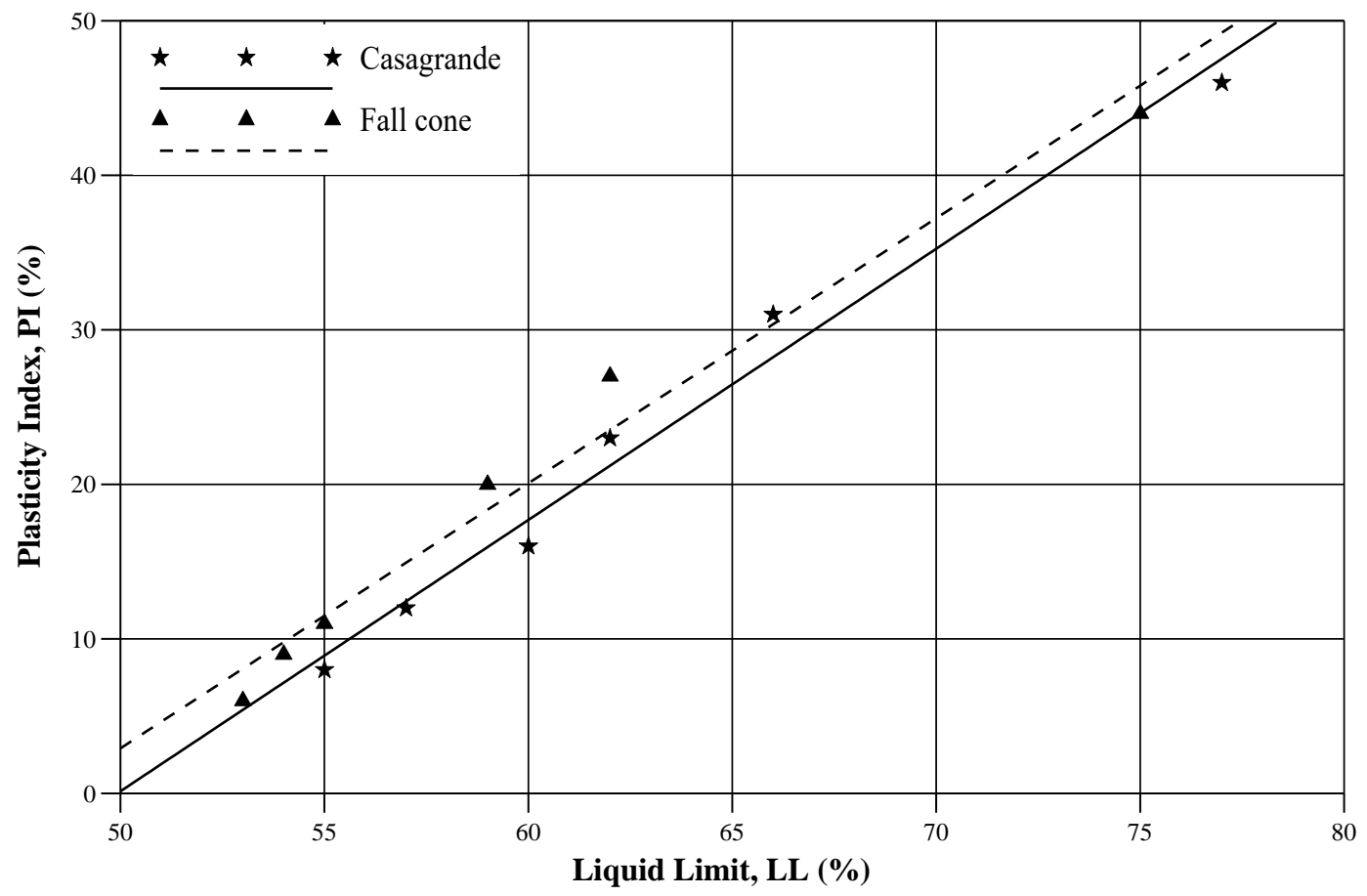

Figure 4 - Correlation of Liquid Limit and Plasticity Index values.

The plasticity index correlated to the liquid limit has lead to the higher correlation coefficients. The lower coefficient, $r$, has been recorded when the linear shrinkage was correlated to the liquid limit values. Better correlations of the liquid limit with all other properties have been recorded when the 
LL had been found using the Casagrande percussion cup test method compared with those found with the fall cone procedure.

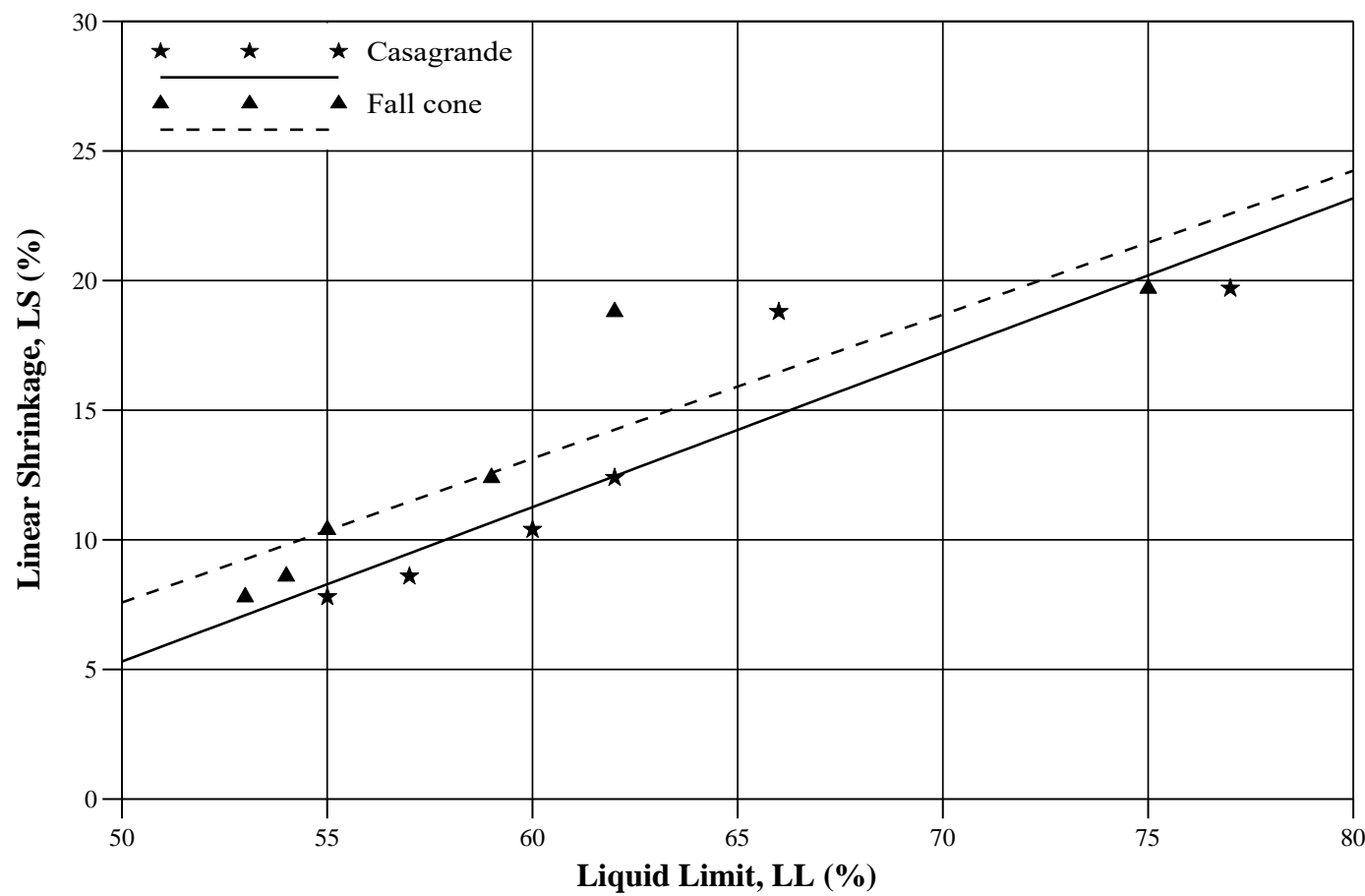

Figure 5 - Correlation of Liquid Limit and Linear Shrinkage values.

\subsection{Correlation of $L L_{\text {cup }}$ and $L L_{\text {cone }}$}

Equations describing the relation of two kinds of liquid limit values $\left(\mathrm{LL}_{\mathrm{cup}}\right.$ and $\mathrm{LL}_{\text {cone }}$ corresponding to the Casagrande and fall cone tests) are summarized in Table 3. The reference for each equation is presented along with the range of LL values for each case.

Table 3 - Proposed LLcone-LLcup equations.

\begin{tabular}{|c|c|c|}
\hline Equation & LL range studied (\%) & Reference \\
\hline $\mathrm{LL}_{\text {cone }}=0.85 \mathrm{LL}_{\text {cup }}+5.02$ & $30-76$ & Karlsson $(1961,1977)$ \\
\hline $\mathrm{LL}_{\text {cone }}=0.95 \mathrm{LL}_{\text {cup }}+0.95$ & $30-72$ & Sherwood and Ryley (1970) \\
\hline $\mathrm{LL}_{\text {cone }}=0.97 \mathrm{LL}_{\text {cup }}+1.60$ & $20-100$ & Littleton and Farmilo (1977) \\
\hline $\mathrm{LL}_{\text {cone }}=0.94 \mathrm{LL}_{\text {cup }}+0.97$ & $38-55$ & Wires (1984) \\
\hline $\mathrm{LL}_{\text {cone }}=0.97 \mathrm{LL}_{\text {cup }}+1.19$ & $34-134$ & Belviso et al. (1985) \\
\hline $\mathrm{LL}_{\text {cone }}=0.67 \mathrm{LL}_{\text {cup }}+15.46$ & $30-550$ & Sivapullaiah and Sridharan (1985) \\
\hline $\mathrm{LL}_{\text {cone }}=1.01 \mathrm{LL}_{\text {cup }}+4.92$ & $27-110$ & Wasti (1987) \\
\hline $\mathrm{LL}_{\text {cone }}=0.86 \mathrm{LL}_{\text {cup }}+6.34$ & $30-74$ & Leroueil and Le Bihan (1996) \\
\hline $\mathrm{LL}_{\text {cone }}=0.86 \mathrm{LL}_{\text {cup }}+4.55$ & $31-86$ & Dragoni et al. (2008) \\
\hline $\mathrm{LL}_{\text {cone }}=0.90 \mathrm{LL}_{\text {cup }}+6.04$ & $30-105$ & Özer (2009) \\
\hline $\mathrm{LL}_{\text {cone }}=1.00 \mathrm{LL}_{\text {cup }}+2.44$ & $21-50$ & Fojtová et al. (2009) \\
\hline $\mathrm{LL}_{\text {cone }}=1.01 \mathrm{LL}_{\text {cup }}+3.49$ & $80-215$ & Grønbech et al. (2010) \\
\hline $\mathrm{LL}_{\text {cone }}=0.95 \mathrm{LL}_{\text {cup }}+9.4$ & $100-340$ & Grønbech et al. (2011) \\
\hline $\mathrm{LL}_{\text {cone }}=1.00 \mathrm{LL}_{\text {cup }}+2.20$ & $24-50$ & Di Matteo (2012) \\
\hline $\mathrm{LL}_{\text {cone }}=0.99 \mathrm{LL}_{\text {cup }}+1.05$ & $20-61$ & Spagnoli (2012) \\
\hline $\mathrm{LL}_{\text {cone }}=1.00 \mathrm{LL}_{\text {cup }}-2.07$ & $14-100$ & Bicalho et al. (2014) \\
\hline $\mathrm{LL}_{\text {cone }}=0.86 \mathrm{LL}_{\text {cup }}+10.98$ & $53-75$ & Current study (2016) \\
\hline
\end{tabular}


The Casagrande cup and fall cone tests do not produce the same results (Wasti, 1987; Prakash and Sridharan, 2006; Özer, 2009). In general, good agreement is observed for soils within an approximate range of $0 \%<\mathrm{LL}<70 \%$. Outside this range, the fall cone test produces consistently lower LL values (Verástegui-Flores and Di Emidio, 2014; Di Mateo et al., 2015).

In the present research the LL values of a lime stabilized clayey soil found using the Casagrande type percussion cap machine and the fall cone methods have been compared. The relationship and difference between the $\mathrm{LL}_{\text {cup }}$ and $\mathrm{LL}_{\text {cone }}$ for the tested clay is shown in Figure 6 with liquid limit ranging from 53 to $77 \%$. A straight line is easily fitted. The following statistical relationship is obtained between the two liquid limits:

$L_{\text {cone }}=1.03 L_{\text {cup }}-4.93$

The correlation of the two limits is very good, as it is denoted by the correlation factor of the fitting equation, $\mathrm{r}=0.99$.

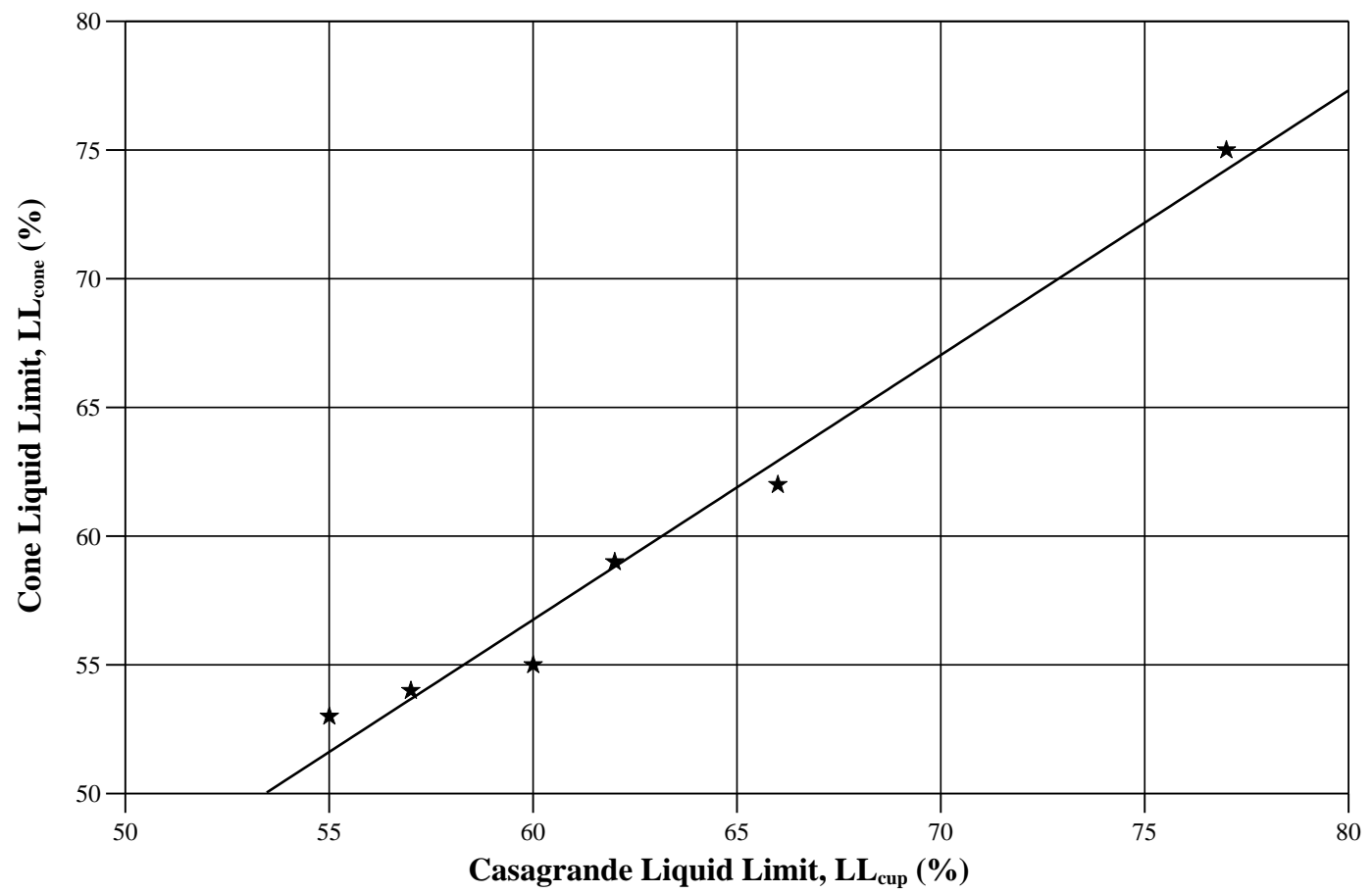

Figure 6 - Correlation of LL values estimated by the Casagrande and fall cone methods.

\section{Conclusions}

In highway construction mechanics, the classification of fine-grained soils is based on consistency as a fundamental parameter. Liquid limit and plastic limit are determined through the Casagrande test or the fall cone test and the hand rolling method, respectively. A serious shortcoming of these techniques is that they are characterized by low repeatability and are operator-dependent. More than a hundred years after Atterberg first described the consistency limits, his original definition could be reviewed and the mechanical interpretation of one of the most basic tests in soil mechanics has to be thoroughly studied and re-established towards the development of a universal specification and standardized equipment.

This paper presents a comparison between the liquid limit values received from tests performed on soil samples using the Atterberg method and the fall cone penetrometer method. The comparison of the two limits is very good, as it is denoted by the correlation factor, $r=0.98$. 
The study determined the different parameters of soil that affect the liquid limit values measured by both methods.

The equations found in literature seem suitable for the prediction of liquid limit assessed by fall cone test and the experimental value achieved by Casagrande device.

A high correlation was also found between the results of both methods for the lime stabilized soil specimens tested in this research work. In either case the LL decreased with the addition of lime. The reduction of the LL value. was higher with the fall cone method.

\section{References}

Allbrook, R.F., 1980. The drop-cone penetrometer method for determining Atterberg limits, N. Z. J. Sci., 23(1), 93-97.

Athanasopoulou, A., 2014. Addition of lime and fly ash to improve highway subgrade soils, J Mater Civil Eng, ASCE, 26(4), 773-775.

Athanasopoulou, A. and Kollaros, G., 2011. Use of additives to improve the engineering properties of swelling soils in Thrace, Northern Greece, Materials Characterisation V, Computational Methods and Experiments, WIT Press, 327-338.

Belviso, R., Ciampoli, S., Cotecchia, V. and Federico, A., 1985. Use of the cone penetrometer to determine consistency limits, Ground Eng., 18(5), 21-22.

Bicalho, K.V., Gramelich, J.C. and dos Santos Cunha, C.L., 2014. Comparação entre os valores do limite de liquidez obtidos pelos métodos de Casagrande e cone para solos argilosos Brasileiros, Comunicações Geológicas, 101(Especial III), 1097-1099.

Budhu, M., 1985. The effect of clay content on liquid limit from fall cone and the British cup device, ASTM Geotech. Test. J., 8(2), 91-95.

Campbell, D.J., 1975. Liquid limit determination of arable topsoils using a drop-cone penetrometer, J. Soil Sci., 26(3), 234-240.

Casagrande, A., 1932. Research on the Atterberg limits of soils, Public Roads, 13(8), 121-130, 136.

Casagrande, A., 1958. Notes on the design of the liquid limit device, Géotechnique, 8(2), 84-91.

Di Matteo, L., 2012. Liquid limit of low- to medium-plasticity soils: comparison between Casagrande cup and cone penetrometer test, Bull. Eng. Geol. Environ., 71(1), 79-85.

Di Matteo, L., Dragoni, W., Cencetti, C., Ricco, R. and Fucsina, A., 2015. Effects of fall-cone test on classification of soils: some considerations from study of two engineering earthworks in Central Italy, Bull. Eng. Geol. Environ., 74, 1-9.

Dragoni, W., Prosperini, N. and Vinti, G., 2008. Some observations on the procedures for the deter mination of the liquid limit: an application on plio-pleistocenic clayey soils from Umbria re gion (Italy), Ital. J. Eng. Geol. Environ., 1, 185-197.

Emami, A.M.R. and Monfared, S.R., 2012. Fall cone test parameters and their effects on the liquid and plastic limits of homogeneous and non-homogeneous soil samples, EJGE, 17, 1615-1646.

Farrell, E., Schuppener, B. and Wassing, B., 1997. ETC 5 fall-cone study, Ground Eng., 30(1), 33-36.

Fojtová, L., Marschalko, M., Franeková, R. and Kovàr, L., 2009. Study of compatibility of methods for liquid limit measurement according to Czech State Standard and newly adopted European Standard, Geosci. Eng., LV(1), 55-68.

Grønbech, G., Nielsen, B.N. and Ibsen, L.B., 2010. Comparison of plasticity index of Søvind marl found by use of Casagrande cup, fall cone apparatus and loss on ignition, Department of Civil Engineering, Aalborg University, DCE Technical Reports, 87, 14 pp.

Grønbech, G.L., Nielsen, B.N. and Ibsen, L.B., 2011. Comparison of liquid limit of highly plastic c lay by means of Casagrande and fall cone apparatus, $14^{\text {th }}$ Pan-American Conference on Soil Mechanics and Geotechnical Engineering, Toronto, ON, 7 pp.

Houlsby, G.T., 1982. Theoretical analysis of the fall-cone test, Géotechnique, 32(2), 111-118.

Karlsson, R., 1961. Suggested improvements in the liquid limit test with reference to flow properties of remoulded clays, Proc $5^{\text {th }}$ Int Conf on Soil Mech Found Eng (ICSMFE), Paris, France, 171-184. 
Karlsson, R., 1977. Consistency limits: A manual for the performance and interpretation of laboratory investigations, Swed Counc Bldg Res, Part 6, Document D6, 40 pp.

Leroueil, S. and Le Bihan, J.-P., 1996. Liquid limits and fall cones, Can. Geotech. J., 33(5), 793-798.

Littleton, I. and Farmilo, M., 1977. Some observations on liquid limit values with reference to penetration and Casagrande tests, Ground Eng., 10(4), 39-40.

Nini, R., 2014. Effect of the silt and clay fractions on the liquid limit measurements by Atterberg cup and fall cone penetrometer, Int. J. Geotech. Eng., 8(2), 239-241.

Özer, M., 2009. Comparison of liquid limit values determined using the hard and soft base Casagrande apparatus and the cone penetrometer, Bull. Eng. Geol. Environ., 68(3), 289-296.

Prakash, K. and Sridharan, A., 2014. Discussion of "Atterberg limits and remolded shear strengthwater content relationships", Geotech. Test J., 37(4), 726-728.

Quintela, A., Costa, C., Terroso, D. and Rocha, F., 2014. Liquid limit determination of clayey material by Casagrande method, fall cone test and EBS parameter, Materials Technology: Advanced Biomaterials, 1(2), B82-B87.

Saeed, K.A.H., Kassim, K.A., Nur, H. and Yunus, N.Z.M., 2013. Characterization of hydrated limestabilized brown kaolin clay, Int. J. Eng. Res. Techn. (IJERT), 2(11), 3722-3727.

Sherwood, P.T. and Riley, M.D., 1970. An investigation of a cone-penetrometer method for the determination of the liquid limit, Géotechnique, 20(2), 203-208.

Sivapullaiah, P.V. and Sridharan, A., 1985. Liquid limit of soil mixtures, Geotech. Test J., 8(3), 111116.

Spagnoli, G., 2012. Comparison between Casagrande and drop-cone methods to calculate liquid limit for pure clay, Can. J. Soil. Sci., 92(6), 859-864.

Verástegui-Flores, D. and Di Emidio, G., 2014. Assessment of clay consistency through conventional methods and indirect extrusion tests, Appl. Clay Sci., 101, 632-636.

Wasti, Y., 1987. Liquid and plastic limits as determined from the fall cone and the Casagrande methods, Geotech. Test J., 10(1), 26-30.

Wires, K.C., 1984. The Casagrande method versus the drop-cone penetrometer method for the determination of liquid limit, Can. J. Soil. Sci., Notes, 64(2), 297-300. 